\title{
Tidal and wind energy conversion duo
}

\author{
Ajinkya Padate \\ Mechanical Engineering, Vidyavardhini’s College Of Engineering and Technology, Mumbai, India
}

Email address:

ajinkyaypadate@gmail.com

\section{To cite this article:}

Ajinkya Padate. Tidal and Wind Energy Conversion Duo. International Journal of Renewable and Sustainable Energy. Vol. 2, No. 4, 2013, pp. 163-166. doi: 10.11648/j.ijrse.20130204.15

\begin{abstract}
The idea that is being explained in the paper is to harness tidal energy and to convert it into electrical energy. The idea is simple but is implemented in a very unique way. The prime mover that is installed is a wind turbine. The atmospheric air will be used to generate electricity but the driving factor which will act as an air pump is tides. It deals with required piping design and the specifications of components required to generate electricity. Here in this paper analysis has been carried out to explain and justify all the proposed aspects and also the advantages and shortcomings are listed.
\end{abstract}

Keywords: Renewable, Wind Turbine, Non-Return Valve

\section{Introduction}

Fast production demands fast utilization of resources. One such major resource is electricity. Electricity is the lifeline for all the industrial work. Rising standard of living and development of technology has made use of appliances imperative in our day to day life. Thus there is also a vast rise in power consumption in residential areas. In order to suffice the growing power demands, we are now largely dependent on the extraction of power from nonconventional, renewable sources of energy. Solar and wind energy are the major forms of renewable energy our mankind look forward to. This paper largely focuses on extracting electrical energy from wind energy.

Over the years wind energy has been used to develop electrical energy and in a very efficient way using wind turbines. The idea behind wind energy to electrical energy conversion is to convert kinetic energy of moving air (wind) into electrical energy. This is a very efficient method that can be implemented in large open spaces to gather fast flowing winds as the energy conversion solely depends on wind velocity. Also huge wind mills have to be constructed that result in heavy installation charges.

Another method to reduce heavy requirement of land is to install wind turbines offshore but that in case increases installation, transport and maintenance costs. But nowadays due to shortage of land, people have started researching on alternative places where a wind farm may be installed and corresponding manipulations in the design of the working cycle. Using a similar approach, a modification is being presented in this paper.
The sequence of the paper starts with governing principle followed by the specifications and requirements of different components to be used and finally the assembly of components and the working process. It should be noted that the modifications are being done in the assembly section and not in the component specifications. The components used are genuine and easily available in the market.

\section{Governing Principle}

Wind energy is the kinetic energy of air in motion, also called wind. Total wind energy flowing through an imaginary area $A$ during the time $t$ is:

$$
E=\frac{1}{2} m v^{2}=\frac{1}{2}(A v t \rho) v^{2}=\frac{1}{2} A t \rho v^{3},[1]
$$

Where $\rho$ is the density of air; $v$ is the wind speed; $A v t$ is the volume of air passing through $A$ (which is considered perpendicular to the direction of the wind); Avt $\rho$ is therefore the mass $m$ passing per unit time. Note that $1 / 2 \rho v^{2}$ is the kinetic energy of the moving air per unit volume.

Power is energy per unit time, so the wind power incident on $A$ (e.g. equal to the rotor area of a wind turbine) is:

$$
P=\frac{E^{\prime}}{t}=\frac{1}{2} A \rho v^{3}
$$

Wind power in an open air stream is thus proportional to 
the third power of the wind speed; the available power increases eightfold when the wind speed doubles. Wind turbines for grid electricity therefore need to be especially efficient at greater wind speeds.

A German physicist Albert Betz concluded in 1919 that no wind turbine can convert more than 16/27 (59.3\%) of the kinetic energy of the wind into mechanical energy turning a rotor. To this day, this is known as the Betz Limit or Betz' Law. The theoretical maximum power efficiency of any design of wind turbine is 0.59 (i.e. no more than $59 \%$ of the energy carried by the wind can be extracted by a wind turbine). This is called the "power coefficient" and is defined as: Cpmax $=0.59$ [2]

Also, wind turbines cannot operate at this maximum limit. The $\mathrm{Cp}$ value is unique to each turbine type and is a function of wind speed that the turbine is operating in. Once we incorporate various engineering requirements of a wind turbine - strength and durability in particular - the real world limit is well below the Betz Limit with values of 0.35-0.45 common even in the best designed wind turbines. Hence, the power coefficient needs to be factored in equation and the extractable power from the wind is given by: $P_{\text {available }}=\left(\rho A v^{3} \mathrm{Cp}\right) / 2[2]$

\section{Methodology}

The method used in the proposed idea is quite simple which is devised using basic principle and formulae. To design the complete system the analysis is carried in a direction from generation of electricity to design of reservoir tank. Our main aim is to charge 12.1 volts battery using tidal energy.

\subsection{Battery Specifications}

A battery cell consists of two lead plates a positive plate covered with a paste of lead dioxide and a negative made of sponge lead, with an insulating material (separator) in between. The plates are enclosed in a plastic battery case and then submersed in an electrolyte consisting of water and sulfuric acid. Each cell is capable of storing 2.1 volts. [4]

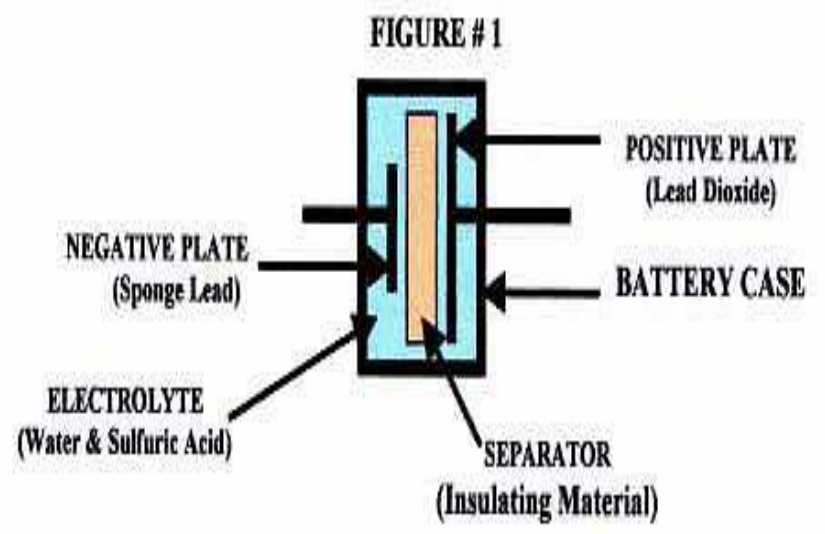

Figure 1: Structure of Basic Lead Acid Battery
In order for lead acid cell to produce a voltage, it must first receive a (forming) charge voltage of at least 2.1volts/cell from a charger. Lead acid batteries do not generate voltage on their own; they only store a charge from another source. This is the reason lead acid batteries are called storage batteries, because they only store a charge. The size of the battery plates and amount of electrolyte determines the amount of charge lead acid batteries can store. The size of this storage capacity is described as the amp hour $(\mathrm{AH})$ rating of a battery. A typical 12 -volt battery used in a RV or marine craft has a rating $125 \mathrm{AH}[4]$, which means it can supply 10 amps of current for 12.5 hours or 20-amps of current for a period of 6.25 hours. Lead acid batteries can be connected in parallel to increase the total AH capacity. To charge a lead acid battery, conventionally the charger should be set at 13.6 volts. [4] This value which is above 12.6 volts is set to reconvert lead sulphate into lead and sulphuric acid.

\subsection{Generator Output and Pressure Required}

Generator capacity and pressure differential required to generate a voltage of 13.6 volts minimum.

A usually available small generator is of the rating $1 \mathrm{KW}$ to $6 \mathrm{KW}$. According to our requirement to charge a battery within 6.25 hour we need 20 amps current. So accordingly total power required is Preq $=$ voltage * current.

Thus Preq $=13.6 * 20=272$ watts.

$\mathrm{B}$ : Using the power output equation

Output $=\mathrm{C}_{\mathrm{poa}} \times \mathrm{A} \times \mathrm{PA} \times \mathrm{G}[1]$

Where:

Cpoa is the aerodynamic power coefficient (efficiency of the rotor to convert energy)

A is the swept area of the blade

$\mathrm{PA}$ is the power density of the wind $=0.6125 \mathrm{x} \mathrm{V}^{\wedge} 3$ where $\mathrm{V}$ is the wind speed in $\mathrm{m} / \mathrm{s}$

$\mathrm{G}$ is the generator efficiency

Here $\mathrm{A}$ is the blade area and for a small wind turbine of rating $1 \mathrm{KW}$ the blade diameter is 1.75 meters. So the effective area is $A=\pi 0.875^{2}=2.405 \mathrm{~m}^{2}$

For a turbine with a 1.75 diameter rotor at a wind speed of ' $\mathrm{V}$ ' $\mathrm{m} / \mathrm{s}$ with a power coefficient of 0.35 (generous!) and a generator effiency of $90 \%$ :

Output $=0.35 \times\left(3.1416 \times(1.75 / 2)^{2}\right) \times\left(0.6125 \times V^{\wedge} 3\right) \times$ $0.9=272 \mathrm{~W}$

Therefore the speed of air required is $8.36 \mathrm{~m} / \mathrm{s}$.

Using Bernoulli's equation of pressure head we get that the pressure differential that will be required is $\mathrm{P}=.5 \rho \mathrm{v}^{2}[1]$ that gives $43.681 \mathrm{~N} / \mathrm{m}^{2}$.

Assuming that the datum head is negligible. Well in any case in the design it gives a significant value then it has to be taken into consideration.

\section{Design of Components}

Now according to the above calculations, we need to design the following components: 


\subsection{Turbines}

The required turbine is a small wind turbine required with a rating of $1 \mathrm{KW}$. The fan blades should be of $1.75 \mathrm{~m}$ in diameter that may sweep a complete area of $2.405 \mathrm{~m}^{2}$.

The AVIN 1000 is designed to operate in a site with low to medium wind speeds $(3.6 \mathrm{~m} / \mathrm{s})$. With a rated output of 1000 watts at $31 \mathrm{mph}$ wind speed, the WHI-200 can make a significant contribution to your alternative energy system. Even with only $5.4 \mathrm{~m} / \mathrm{s}$ average wind speed, The Whisper 200 provides about $158+\mathrm{kWh}$ per month $(5.3 \mathrm{kWh}$ per day)

Thus according to availability of wind turbines in India a suitable wind turbine can be installed.

\subsection{Non Return Valve}

A Non Return Valve is a device which allows the flow of fluid in only 1 direction. The flow is restricted in the other direction. The use of this valve in the design is basically to control the flow of air from one reservoir of air to another. This will ensure increase in pressure of air contained in the reservoir since there is no leakage of air. So according to collected data a non return valve with a pressure rating stated PN 1.6 can be selected which can handle a maximum pressure of 16 bar which is huge compared to what the design is expected to experience.[5] The maximum pressure that the pressure valve can allow also matches with the specifications of non return valve.

Table 1: Hydraulic Test Results on Valves

\begin{tabular}{lllll}
\hline Rating & $\begin{array}{l}\text { Max } \\
\text { pressure }\end{array}$ & \multicolumn{2}{l}{$\begin{array}{l}\text { Hydrostatic test } \\
\text { pressure (bar) }\end{array}$} & $\begin{array}{l}\text { Test } \\
\text { duration }\end{array}$ \\
\hline & bar & body & seat & Minutes \\
PN 0.6 & 6 & 9 & 6 & 2 \\
PN 1.0 & 10 & 15 & 10 & 2 \\
PN 1.6 & 16 & 24 & 16 & 2 \\
\hline
\end{tabular}

The above table provides data about the pressure handling capacity of valves taken from the catalogue of kirloskar companies. The weaker part in the assembly of a valve is the valve seat. That's why the maximum pressure that a valve can handle is actually the maximum pressure the valve seat can handle. Here the test duration is 2 minutes but in actual implementation it is up to $6 \mathrm{hrs}$ thus a valve of rating PN 1.6 should be selected to make the design safe.

\subsection{Reservoir}

The reservoir is a tank that has to be mounted to hold air. A separate reservoir exists which is exposed to the atmosphere. The reservoir has to be connected to the tank through the non return valve. A $1 \mathrm{~m}^{3}$ tank will make the tank capable of producing $100 \mathrm{~kJ}$ of power if air is at atmospheric pressure. [6]

\section{Working}

The complete assembly works on tidal flow. Let this assembly be installed on the coasts which are not beaches to ensure natural splashing of sea waves. Initially the lower tank which is open to atmosphere will be filled with atmospheric air at 1 bar. Then during High Tide Sea waves will splash on the opening which will force the entrapped air to enter the reservoir through the non return valve. The high time occurs for $12 \mathrm{hrs}$ and 25 minutes in a day [7].

But taking into consideration the time taken by the tides to slowly rise up to its peak amplitude and to retreat during the commencement of low tide, the effective working time of the plant at high tides in near about 6hrs. During these 6 hrs the entrapped air will be forced into reservoir and it will not return due to the non return valve.

Gradually the mass density of air in the reservoir will increase and the pressure inside the reservoir will increase as the volume is constant.

The pressurized air will be collected during high tide. During low tide this pressurized air will be sent through a pressure valve followed by a nozzle into the wind turbine. A max pressure that can be generated in the $1 \mathrm{~m}^{3}$ tank is 16 bars which is the capacity of valve thus a maximum of $1.6 \mathrm{MJ}$ of energy can be converted into electrical energy. If the volume of reservoir is increased then the amount of energy generated can be increased. It should be noted that the tide which should strike the opening should block the opening almost completely so that the displaced air to be entrapped is not escaped.

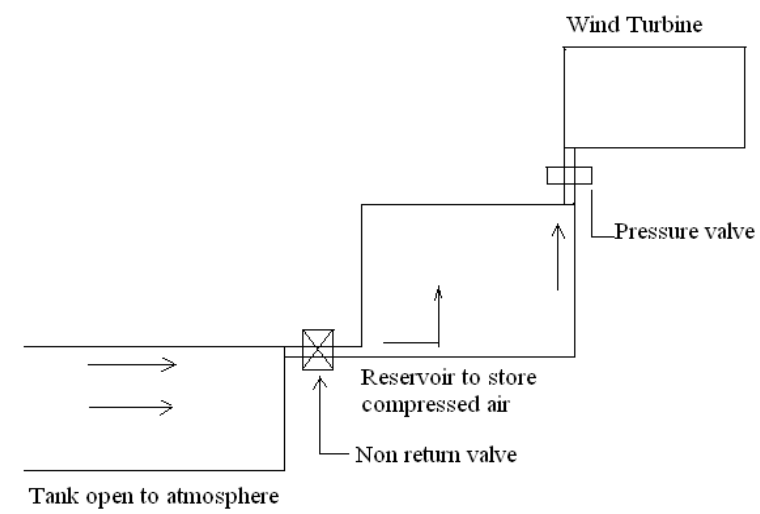

Figure 2: Layout of Assembly of Components

Thus if the observations are studied then it is seen that the wind turbine produces $1.6 \mathrm{MJ}$ of energy when it operates at maximum allowable pressure. If the discharge rate is adjusted between the reservoir and the turbine such that the entire volume of entrapped air is discharged in an hour i.e. a discharge rate of $2.78 * 10^{\wedge}-4 \mathrm{~m}^{3} / \mathrm{s}$ (assumed a lower value). Then it can be stated that the turbine can produce $444.45 \mathrm{~W}$ of power which can generate a current of $32.68 \mathrm{amps}$ which in turn will charge a battery of $125 \mathrm{AH}$ rating in $3.825 \mathrm{hrs}$. The discharge value is very low assumed. More the discharge value greater the power produced. 


\section{Benefits and Drawbacks}

\subsection{Benefits}

1. The energy that is being converted into electricity was previously wasted completely.

2. The turbine is a gas turbine thus due to less amount of water vapour in the working fluid will increase the life of turbine blades.

3. This is a clean source of energy with zero pollutant emissions.

4. Use of new renewable sources of electricity is the need of the day and advancement in turbine industry will improve the output capacity.

5. It does not depend on weather conditions like sunny, rainy season etc. since tides are a continuous source of energy irrespective of the season

\subsection{Drawbacks}

1. Power developed by this method will be very low for practical use. The energy generated would be required to store in batteries and then used which will increase the system cost

2. The turbines and reservoir tanks to be installed are costly components.

3. The system works for effectively only $6 \mathrm{hrs}$ a day. That means that only $25 \%$ of its total capacity is being harnessed.

4. The major difficulty lies in selecting a proper site to implement such a project since the installation charges would also apply. A proper study will be required to carry out exact site location of plant.
5. Due to low power generation in its preliminary form, the payback period of this plant is high.

\section{Conclusion}

The current power output of this plant is low. The high investment costs and long payback period makes it difficult for people to believe in the potential of this system. But this system is in its cradle state. Future improvements and development in field of turbines will definitely improve the efficiency of this power plant.

\section{References}

[1] "Harvesting the Wind: The Physics of Wind Turbines" (PDF). Retrieved 2013-01-1

[2] Basic Engineering Mathematics, John Bird, 2007, published by Elsevier Ltd.

[3] DOE-HDBK-1084-95; Primer on lead acid storage batteries.

[4] Renewable energy sources charged with energy from the sun and originated from the Earth- Moon interaction -Vol IITidal Energy- I N Ushachev

[5] Kirloskarpumps.com/download/prod_catalogue/swingcheck. $p d f$

[6] Applied Thermodynamics- R.K.Rajput

[7] "Types and causes of tidal cycles". U.S. National Oceanic and Atmospheric Administration (NOAA) National Ocean Service (Education section) 